\section{Minipress (DrazOSInHCl)}

Reterences: 1. Lund-Johansen P: Hemodynamic changes at rest and during exercise in long-term prazosin therapy for essential hypertension, in Prazosin Clinical Symposiun Proceedings. Published as a special report by Postgraduate Medicine New York. McGraw Hill Co, 1975. pp 45-52. 2. Komajda M: Prazosin and lipids: A study of the effects of prazosin on blood lipids in hypertensive patients. Impact int December 1986; (special issue): 1.4 J. Routty J. Jaillard J: Effects of two anthypertensive agents on lipids. lipoproteins, and $24)-100-103$. 4. Lowenstein J. Neusy A.J. Effects of prazosin and propranolol on serum ids in patients with essential hypertension. Am J Med 1984; 76(2A):79.84. 5. Stamler R Stamler J, Gosch FC, et al: Initial antihypertensive drug therapy: A comparison of alpha blocker (prazosin) and diuretic (hydrochiorothiazide): Final report of a randomized, con trolled trial. In press. 6. Leren P. Helgeland A, Holme I, et al: Effect of propranolol and prazosin on blood lipids: The Oslo Study. Lancet 1980; 11:4-6.7. Kwan CM. Shepherd AMM, Johnson J. et al: Forearm and finger hemodynamics, blood pressure control and lipid changes in patients with diabetic hypertension treated with atenoiol and prazosin. Cin ediary metabolism in diabetic patients. $J$ Cardiovasc Med 1981:(special suppi): $38-42$

\section{Brief Summary}

Tesin hydrochloride) CAPSULES

For Oral Use ment of hypertension. It is mild to moderate in activity and can be used as the initial agento ( drugs as needed. CONTRAINDICATIONS: None knOWn. WARNINGS: MINIPRESS ma cause syncope with sudden loss of consciousness. In most cases this is believed to be due to an excessive postural hypotensive effect, although occasionally the syncopal episode has been preceded by a bout of severe tachycardia with heart rates of 120 - 160 beats per minute. Syncopal episodes have usually occurred within 30 to 90 minutes of the
initial dose of the drug: occasionally they have been reported in association with rapic dosage increases or the introduction of another antilinypertensive drug into the regimeno a patient taking high doses of MINIPRESS. The incidence of syncopal episodes i aproximately $1 \%$ in patients given an initial dose of $2 \mathrm{mg}$ or greater. Clinical trial. can be minimized by limiting the initial dose of the drug to $1 \mathrm{mo}$, by subseguent increasing the dosage slowly, and by introducing any additional antihypertensive drug into the patient's regimen with caution (see DOSAGE ANO ADMINISTRATION). Hypoten sion may develop in patients given MINIPRESS who are also receiving a beta-blocke such as propranolol. If syncope occurs, the patient should be placed in the recumbent position and treated supportively as necessary. This adverse effect is self-limiting and in most cases does not recur after the initial period of therapy or during subsequent dose titration. The patient should also be cautioned to avoid situations where injury could result should syncope occur during the initiation of MINIPRESS therapy. PRECAUTIONS: Informa-

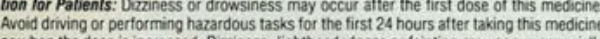
or when the dose is increased. Dizziness, lightheadedness or fainting may occur, especiall when rising from a lying or sitting position. Getting up slowly may help lessen the problem These effects may als occur it you drink alcohol, stand for long periods of time, exercise,
it the weather is hot. While taking MNIPRESS, be careful in the amount of alcohol you drink Also, use extra care during exercise or hot weather, or it standing for long periods. Chec with your physician if you have any questions. Orug Interactions: MiviPRESS has beer
wis. administered without any adverse drug interaction in limited clinical experience to date with che folliowing: (1) cardiac glycosides-digitalis and digoxin; (2) hypoglycemics-insulic chlorpropamide. phenformin, tolazamide, and tolbutamide; (3) tranquilizers and sedatives. chlordiazepoxide, diazepam, and phenobarbital; (4) antigout-allopurinol, colchicine. anc prenecid, (5) antiartitythmics-procainamide, propranoilal (see WARNINGS however), an inter MVIIPRESS has been shoun to cause an additive hypotensive eftect. Orug / Laboratory Interactions: False positive results may occur in screening tests tor pheochromocytoma patients who are being treated with prazosin. II an elevated VMA is found, prazosin should be oiscontinued and the patient retested after a month. Laboratory Tests: In clinical studies in which lipid profiles were followed, there were generally no adverse changes noted betwee. pre- and post-treatment lipid levels. Carcinogenesis, Mutagenesis, Impairment of Fer tiilty: No carcinogenic potential was demonstrated in an 18 month study in rats with MINIPRESS (prazosin hydrochloride) at dose levels more than 225 times the usual maximur recommended human dose of $20 \mathrm{mg}$ per day. MINIPRESS was not mutagenic in in wiv penetic toxcology studies. In a tertility and general reproductive performance study in rats males and temales. treated with $75 \mathrm{mg} / \mathrm{kg}$ (225 times the usual maximum recom

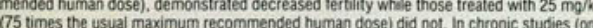
vear or more of MUN PRESS in rats and dogs, testicular changes consisting of atrophy a necrosis occurred at $25 \mathrm{mg} / \mathrm{kg} / \mathrm{day}(75$ times the usual maximum recommended hum dose). No testicular changes were seen in rats or dogs at $10 \mathrm{mg} / \mathrm{kg} / \mathrm{day}$ ( 30 times the usu animals, 105 patients on long term MINIPRESS therapy were monitored for 17 -ketostero excretion and no changes indicating a drug effect were observed. In addition, 27 males 0 MINIPRESS for up to 51 months did not have changes in sperm morphology suggestive c arug effect. Usage in Pregnancy: Pregnancy Category C. There are no adequate and we controlied studies which establish the satety of MINIPRESS (prazosin HCi) in pregnan 政 be pletid in is administered to a nursing have not been established ADVERSE REACTIONS: Clinical trials were conducted chidore than 900 patients. During these trials and subsequent marketing experience, the mon

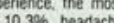
$8 \%$, drowsines $7.6 \%$, lack with MINIPRESS therapy are. dizziness $10.3 \%$, headache nausea 4.996. In most instances side effects have disappeared with continued therapy o have been tolerated with no decrease in dose of drug. Less frequent adverse reactions whic are reported to occur in $1-4 \%$ of patients are: Gastrointestinal: vomiting, diarrhea, constip n, Caroiovascular: edema, orthostatic hypotension, dyspnea, syncope: Central Nervou Stem: vertigo, depression, netvousness; Dermatologic: rash; Genitourinary: urinary fre dition. asal relationships ha patients have reported the following (in some instances, exac and/or pain, liver function abnormalities, pancreatitis; Cardiovascular tachycardia; Cente Nervous System: paresthesia, hallucinations: Dermatologic: pruritus, alopecia, liche olanus: Genitourinary incontinence, impotence, priapism; EENT tinnitus; Other diaphore sis, fever. Single reports of pigmentary mottling and serous retinopathy, and a few reports Etaract development or disappearance have been reported. OVERDOSAGE: Should ove Josage lead to hypotension, support of the cardiovascular system is of first importanci Restoration of blood pressure and normalization of heart rate may be accomplished b eeping the patient in the supine position. If this measure is inadequate. shock should first b expanders. If necessary. vasopressors should then be used. Rena Cetion should be monitored and supported as needed. Laboratory data indicat the dose of MINIPRESS should be adjusted according to individual blood pressure e slowly increased to a total daily dose of 20 mg given in divided doses. The therape ma rosages most commonly employed have ranged from $6 \mathrm{mg}$ to $15 \mathrm{mg}$ dally given uvided doses. Doses higher than $20 \mathrm{mg}$ usually do not increase etflicacy: however a jatients may benefit from further increases up to a daily dose of $40 \mathrm{mg}$ given in divide oses. After initial tutration some patients can be maintained adequately on a twice dal 10sage regimen. Use With Other Drugs: When adding a diuretic or other antihyperter ive agent, the dose of MINIPRESS should be reduced to $1 \mathrm{mg}$ or $2 \mathrm{mg}$ three times a da Ind retitration then carried out.
Revised December 1988

\section{Review}

\section{Medical Tests and Diagnostic Procedures: A Patient's Guide to Just What the Doctor Ordered}

By Philip Shtasel, DO. Pp 316, with illus. Harper \& Row Publishers, Inc, 10 East 53rd St, New York, 10022, $1990, \$ 22.50$.

\section{Medical Tests and Diagnostic} Procedures: A Patient's Guide to Just What the Doctor Ordered is a book long overdue but well worth the wait. Patients and their physicians will enjoy Dr Shtasel's easy, folksy writing style. He takes the reader on an escorted tour, visiting most specialists and "walking through" most of the investigative procedures that physicians request and patients experience. The book is intended to serve as a reference for anyone who has been advised to undergo a diagnostic procedure or who is referred to a specialist.

The book's organization reflects the usual way in which the physician begins the diagnostic journey: "Go see an allergist;" "Go get an allergy test." Each recommendation has its own chapter describing the events that can occur. The author has developed a simple, yet unique, method of rating discomfort and hazards associated with each procedure. His rating system ranges from - (least uncomfortable or hazardous) to ++++ (most intense). For example, he describes the pain associated with administration of a local anesthetic in this way. "You will experience a + discomfort from the needle stick, $\mathrm{a}++$ discomfort from the sharp burn that follows, and then joy for the almost instantaneous numbness that results."

Why is such a book needed? We physicians frequently fail to explain in detail the actual experience of undergoing the test. Yet, it is impossible for us to keep abreast of all of the new diagnostic techniques and subsequent modifications. In many situations, we may have no idea what the experience is like and, therefore, cannot explain it to the patient.

That's where this book comes in handy. A popular book written by an osteopathic physician and published by a major publishing house, Medical Tests and Diagnostic Procedures: A Patient's Guide to Just What the Doctor Ordered will be invaluable to physicians and patients alike. Your patients will buy this book-and so will you.

THOMAS WESLEY ALLEN, DO Editor in Chief 